\title{
ANALISIS IMPLEMENTASI FULL DAY SCHOOL TERHADAP RESPON ORANG TUA SISWA SEKOLAH DASAR ISLAM TERPADU (SDIT) SAMAWA CENDEKIA KABUPATEN SUMBAWA
}

\author{
Ofah Syarofatunnis ${ }^{1 *}{ }^{2}$ Muhammad Saleh ${ }^{2}$, Lukamanul Hakim \\ 1*Mahasiswa Program Studi pascasarjana Menajemen Inovasi. Universitas Teknologi Sumbawa \\ ${ }^{2}$ Direktur Pascasarjana Menajemen Inovasi. Universitas Teknologi Sumbawa \\ ${ }^{3}$ Dosen Fakultas Psikologi Universitas Teknologi Sumbawa \\ *Corresponding Author email: muhammad.saleh@uts.ac.id,lukmanul.hakim@uts.ac.id
}

\begin{tabular}{|c|c|}
\hline & Abstrak \\
\hline $\begin{array}{l}\text { Diterima : } \\
\text { Bulan Juni } 2020\end{array}$ & $\begin{array}{l}\text { Sistem full day school dilakukan guna memfasilitasi para peserta didik dengan strategi } \\
\text { dan metode yang dapat memberikan pembelajaran aktif dan menyenangkan. Kegiatan } \\
\text { pembelajaran sehari penuh dapat membangun kecerdasan interpersonal seperti kepekan } \\
\text { sosial, pemahaman sosial dan sosial communiction (komunikasi sosial). Penelitian }\end{array}$ \\
\hline $\begin{array}{l}\text { Diterbitkan : } \\
\text { Bulan Juli } 2020\end{array}$ & $\begin{array}{l}\text { bertujuan untuk menganalisa pelakasanaan sistem full day school untuk membangun } \\
\text { kecerdasan interpersonal siswa, peran guru dan piha sekolah dalam membangun } \\
\text { kecerdasan interpesonal siswa, dan hambatan yang dihadapi guru dan sekolah dalan } \\
\text { melasanakan sistem full day school. Metode penelitian yang digunakan adalah metode }\end{array}$ \\
\hline Keyword: & $\begin{array}{l}\text { kualiatif. Populasi penelitian ini adalah seluruh siswa dan orang tua siswa SDIT Samawa } \\
\text { cendekia yang berjumlah } 1244 \text { orang. Jumlah sample penelitian ini adalah } 33 \text { orang dari }\end{array}$ \\
\hline Implementasi, & jumlah populasi. Teknik pengumpulan data yaitu dokumentasi, angket, dan dokumen dari \\
\hline Full day & sekolah, dan guru. Teknik analisis data penelitian ini menerapkan analisis \\
\hline school & fullday shool terhadap respon orang tua siswa di Sekolah Dasar Islam Terpadu Sumbawa \\
\hline & $\begin{array}{l}\text { Cendekia sangant signifikan. Alasannya, pelaksanaan sistem full day school membangun } \\
\text { kecerdasan baik menanam sikap sosial dan komunikasi sosial maupun keteladanan. }\end{array}$ \\
\hline
\end{tabular}

\section{A. PENDAHULUAN}

Undang-Undang No. 20 Tahun 2003 tentang sistem pendidikan menyatakan bahwa Pendidikan adalah usaha sadar dan terencanauntun mewujudkan suasana belajar dan proses pembelajaran agar peserta didik secara aktif mengembangkan potensi dirinya untuk memiliki kekuatan spiritual keagamaan, pengendalian diri, kepribadian, kecerdasan, akhlak mulia. Hal ini menunjukkan bahwa pendidikan adalah suatu proses pembelajaran pengetahuan, keterampilan, dan kebiasaan sekumpulan manusia yang diwariskan dari generasi ke generasi selanjutnya melalui pengejaran, pelatihan, dan penelitian.

Kemudian, pendidikan adalah proeses menuntut segala kekuatan kodrat yang ada pada ana-anak peserta didikan, agar sebagai manusia dan sebagai anggota masyarakat dapat mencapai keselamatan dan kebahagiaan setingi-tingginya (Ki Hajar Dewantara, 1994). Sementara pendidikan adalah upaya menolong anak untuk dapat melakukan tugas hidupnya secara mandiri supaya dapat bertanggung jawab secara susila (Mertinus Jan Lengeveld, 20190). Jadi, pendidikan merupakan usaha manusia dewasa dalam membimbing manusia yang belum dewasa menuju kedewasaan.

Menyikapi keberadaan pendidikan nasional untuk membentuk pribadi generasi bangsa indonesia yang baik dan berkemajuan, maka diperlukan suatu pendidikan yang fulltime disebut full day school. Pendidikan full day school yaitu suatu pendidikan yang memuat dua kuriukulum yaitu kurikulum nasional dan kurikulum pendidikan islam. Alasannya, untuk melengkapi kebutuhan anak didik akan pendidikan seperti pendikan islam yang membutuhkan keluangan waktu untuk 
mendidik, membina, dan mengarahkan anak didik. Salah satu sekolah yang menerapkan sistem pendidikan full day school adalah Sekolah Dasar Islam Terpadu (SDIT) yang berada di kabupaten sumbawa, Nusa Tenggara Barat.

$$
\text { Full day school adalah sistem KBM }
$$

(Kegiatan Belajar Mengajar) telah direncanakan oleh kemendikbud RI pada tahun 2017 silam yang kemudian bermunulan hingga saaat ini. Permendikbud Nomor 23 tahun 2017 menjelaskan bahwa full day school artinya hari sekolah harus berlangsung 8 jam perhari dari senin sampai juma'at mulai pukul 06.45-15.30 WIB, dengan durasi istirahat setiap dua jam sekali. Durasi KBM ini juga sesuai dengan kurikulum tahun 2013.

Pada hakikatnya sistem pembelajaran full day school tidak hanya mengupayahkan dalam menambah waktu dan memperbanyak materi pelajaran saja. Namun lebih dari itu yaitu untuk mengkondisikan anak agar memiliki pembiasaan hidup yang baik, untuk pengayaan atau pendalaman konsep-konsep materi pelajaran yang telah ditetapkan oleh Diknas dan memasukkan materi-materi keIslaman ke dalam bidang studi, agar bisa dikuasai oleh anak-anak untuk bekal hidupnya. Intinya dari sistem pembelajaran full day school ialah bisa memberikan keseimbangan antara kebutuhan rohani dan jasmani, agar terbentuk kepribadian yang utuh.

Pada sistem pembelajaran full day school siswa akan menghabiskan waktu yang lebih banyak disekolah. Harapkannya, siswa akan mendapatkan proporsi pendalaman teori-praktek yang lebih banyak. Pemerintah mengharapkan bahwa aktivitas sekolah seharian penuh seperti tersebut dapat menghadirkan cara belajar yang menyenangkan, interatif, dan praktis. Jadi, selain kegiatan belajar mengajar dikelas, peserta didik juga akan mendapatkan waktu kegiatan ekstrakulikuler yang dapat mendukung keterampilan emosional, psikologis, serta sosialnya. Contohnya adalah kegitan mengaji (jika disekolah islam), pramuka, palang merah, atau jenis ekskul lainya.

Sistem pembelajaran full day school merupakan program pendidikan yang seluruh aktivitas berada di sekolah (sekolah sepanjang hari dengan ciri integrated activity dan integrated curriculum). Artinya seluruh program dan aktivitas anak yang di sekolah, mulai dari belajar, bermain, makan dan beribadah termasuk semua dalam suatu sistem pembelajaran full day school.

Akibat dari adanya sistem pembelajaran full day school, orang tua memasukkan anak ke full day school dengan harapan dapat memenuhi kebutuhan perkembangan anak, mengajarkan agama dan moral kepada anak, dan mengoptimalkan perkembangan anak, khususnya pada perilaku sosialnya mereka. Namun fenomena saat ini, hanya anak-anak hebat yang bisa mengikuti sistem pembelajaran full day school dengan waktu dan jadwal yang telah mendominasi mereka sepanjang hari.

Berdasarkan pantauan langsung bahwa Sekolah Dasar Islam Terpadu (SDIT) Samawa Cendekia di Kabupaten Sumbawa menerapakan sistem pembelajaran full day school. Al-hasil, siswa lebih banyak ada disekolah, guru banyak berperan memotivasi, membina, mendidik, dan mengajarkan anak didik. disamping itu, kurikulum yang diterapkan di Sekolah Dasar Islam Terpadu (SDIT) Samawa Cendekia di Kabupaten Sumbawa berupa kurikulum sesuai dengan pendidikan islam yang berintegrasi dengan kurikulum pendidikan nasional. Dampaknya, anak dan guru lebioh banyak menghabiskan waktu di sekolah daripada di lingkungan masyarakat. Kondisi tersebut, anak didik lebih banyak belajar dan bermain bersama temannya. Sementara guru atau pendidik disamping mengajar dan membina juga meracik kegiatan yang sepadan dengan tujuan sekolah terpadu yang dapat menghilangkan kejenuhan siswa. Akan tetapi, pada proses pembelajaran dan keadaan sosial siswa apakah anak didik dapat 
fokus belajar atau jenuh dengan lingkungan bermain yang monoton. Untuk itu, perlu studi langsung di lapangan untuk menemukan jawabannya.

\section{B. RUMUSAN MASALAH}

1. Bagaimana Sistem Pembelajaran Full day school di Sekolah Dasar Islam Terpadu (SDIT) Samawa Cendekia di Kabupaten Sumbawa,?

2. Bagaimana Perilaku Sosial Siswa di Sekolah Dasar Islam Terpadu (SDIT) Samawa Cendekia di Kabupaten Sumbawa?

3. Bagaimana respon orang tua siswa terhadap full day school di Sekolah Dasar Islam Terpadu (SDIT) Samawa Cendekia di Kabupaten Sumbawa?

\section{TUJUAN PENELITIAN}

1. Untuk Mengetahui Sistem Pembelajaran Full day school di Sekolah Dasar Islam Terpadu (SDIT) Samawa Cendekia di Kabupaten Sumbawa.

2. Untuk Mengetahui Perilaku Sosial Siswa di Sekolah Dasar Islam Terpadu (SDIT) Samawa Cendekia di Kabupaten Sumbawa.

3. Untuk mengetahui respon orang tua siswa terhadap full day school di Sekolah Dasar Islam Terpadu (SDIT) Samawa Cendekia di Kabupaten Sumbawa

\section{MANFAAT PENELITIAN}

1. Dapat dijadikan acuan dalam rangka perngembangan implementasi sistem full day Shcool di SDIT Samawa Cendekia Kabupaten sumbawa

2. Sebagai referensi dan bahan perbandingan bagi lembaga pendidikan lainya dalam merapkan sistem full day school .

\section{E. LANDASAN TEORI}

\section{Sejarah Full Day School}

Sistem full day school pertama kali muncul pada awal tahun 1980-an di Amerika Serikat yang yang pada waktu tersebut diterapkan pada sekolah taman kanak-kanak. Melihat adanya perkembangan afektif siswa taman kanak-kanak, maka penerapan sistem full day school melebar ke jenjang sekolah dasar hingga menengah atas.

Alasannya, terdapat beberapa faktorfaktor dari masyarakat AS diterapkan Full Day School diantaranya:

a. Meningkatnya jumlah orang tua, terutama ibuyang bekerja dan memiliki anak dibawah 6 tahun. 2) Meningkatnya jumlah anak-anak usia prasekolah yang ditampung di sekolah-sekolah milik publik/masyarakat umum.

b. Meningkatnya pengaruh televisi dan kesibukan (mobilitas) orang tua.

c. Keinginan untuk memperbaiki nilai akademik agar sukses menghadapi jenjang yang lebih tinggi.

Selain itu, Full Day School bermunculan diakibatkan oleh:

a. Sekolah yang hanya menggunakan Half Day School sehingga tidak mampu menjamin kualitas siswa, tidak mampu mengontrol aktivitas murid-muridnya setelah selesai waktu belajar, tidak membekali lulusan dengan kecakapan individu karena misinya yang utama adalah optimalisasi IQ anak dengan ukuran ujian akhir.

b. Masyarakat di perkotaan semakin disibukan oleh tuntutan biaya hidup, maka para orang tua menjadi tidak sempat untuk mengawasi aktivitas anak-anaknya. Akibatnya, banyak terjadi tindak kriminal yang dilakukan oleh anak-anak, malas belajar, kecanduan game dan kasuskasus lainnya. 
c. Aktivitas anak yang kurang aktif dalam belajar dapat diarahkan menjadi lebih aktif dengan menambah jam belajarnya lebih lama dari pada sekolah -konvensiaonal. Anak-anak dididik, diatur dan fasilitasi oleh sekolah.

Mencermati keadaan yang tengah berlangsung, maka sebagian masyarakat Amerika beramai-ramai untuk menyekolahkan anaknya di Full Day School. Tujuannya, untuk memperbaiki nilai akademik buah hatinya sehingga kelak sukses menghadapi jenjang yang lebih tinggi. Selain itu,

Sejarah tersebut membuktikan bahwa penerapan full day school adalah salah satu karya cerdik para pemikir dan praktisi pendidikan untuk menyiasati minimnya kontrol orang tua terhadap anak di luar jamjam sekolah formal sehingga sekolah yang awalnya dilakukan 5 sampai 6 jm berubah menjadi 8 bahkan sampai 9 jam (Susanti dan Asyhar, 2015). Selaras dengan itu, sekolah seharian atau Full day school meupakan suatau proses pembelajaran yang dilakukan sehari penuh yang menerapkan dasar integrated curiculum dan yang berarti hampir seluruh aktivitas anak berada disekolah, mulai dari belajar, makan, bermain, dan sekolah dikemas dalam dunia pendidikan (Hilalah, 2009). Maka dari itu, adanya sekolah seharian atau full day school kondisi anak lebih matang dari segi materi akademik dan non akademik. Dengan berbagai strategi yang dikembangkan oleh sekolah full day Shcool peserta didik lebih rileks, tidak terburu-buru dalam melakukan aktivitas sehari-hari dan memberi pengalaman baru yang bervariasi.

\section{Konsep Dasar Full Day School}

Secara etimologi kata Full Day School berasal dari bahasa Inggris. Full mengandung arti penuh, dan Day artinya hari. Maka, full day mengandung arti sehari penuh. Sedangkan School mengandung arti sekolah. Jadi, Full Day School jika dilihat dari segi etimologinya berarti sekolah atau kegiatan belajar yang dilakukan sehari penuh. Sedangkan, terminologi atau arti luas Full Day School mengandung arti sebuah sistem pembelajaran yang dilakukan dalam kegiatan belajar mengajar yang dilaksanakan sehari penuh dengan memadukan system pengajaran secara intensif yaitu dengan memberi tambahan waktu khusus untuk pendalaman yang berlangsung selama lima hari setiap pekan yang dimulai pada pukul 07.00 pagi hingga 15.00 sore, sedangkan hari sabtu tetap masuk sekolah yang biasanya diisi dengan relaksasi dan kreatifitas.

\section{Faktor Pendukung Pendidikan Full Day School}

Adapun faktor-faktor yang mendukung pendidikan Full Day School sebagai berikut:

a. Siswa jelas akan mendapatkan metode pembelajaran yang bervariasi dan lain daripada sekolah dengan program reguler.

b. Orang tua tidak akan merasa khawatir, karena anak-anak akan berada seharian di sekolah yang artinya sebagian besar waktu anak adalah untuk belajar.

c. Orang tua tidak akan takut anak akan terkena pengaruh negatif karena untuk masuk ke sekolah tersebut biasanya dilakukan tes (segala macam tes) untuk menyaring anakanak dengan kriteria khusus (IQ yang memadai, kepribadian yang baik dan motivasi belajar yang tinggi).

d. Meningkatkan semangat orang tua yang memiliki orientas terhadap halhal yang sifatnya ilmu pengetahuan.

e. Obsesi orang tua akan keberhasilan pendidikan anaknya. Alasannya, orang berpikir jika anak mau pandai 
harus dicarikan sekolah yang bagus, dan sekolah bagus itu adalah yang mahal) memiliki peluang besar untuk tercapai. Mungkin banyak lagi halhal "positife lainnya yang tidak tersebut di sini. Jelas kondisi-kondisi tersebut akan muncul dan menjadi pilihan yang menjanjikan bagi anak dan orang tua.

\section{Faktor penghambat Pendidikan Full Day School.}

Adapun yang menjadi pengahambat tumbuh-kembangnya pendidikan Full Day School adalah sebagai berikut:

a. Biaya yang sangat mahal, hal ini disebabkan karena sekolah menyesuaikan kebutuhan dan kualitas para staf pengajar yang selalu berada di sekolah, serta penanganan manajemen sekolah untuk terus menjaga rasio keseimbangan jumlah siswa, staf pengajar dan ruang belajar.

b. Kelengkapan sarana dan prasarana yang dibutuhkan seperti tambah ruang kelas, kelengkapan transportasi khusus dan pemeliharaan gedung sekolah yang membawa susasana berbeda agar tidak membosankan siswa dan gurunya.

c. Kurang dekatnya hubungan antara siswa dengan keluarga menjadikan siswa jauh dari keluarga dan membuat komunikasi semakin berkurang.

d. Dana bagi lembaga pendidikan yang terbatas atau kurang menyebabkan lembaga pendidikan memaksakan keuangan yang tidak semestinya tergantung pada siswa.

\section{F. HASIL DAN PEMBAHASAN}

\section{Hasil}

a. Sistem Pembelajaran Full day
school di Sekolah Dasar Islam $\begin{array}{lcr}\text { Terpadu } & (\text { SDIT }) & \text { Samawa } \\ \text { Cendekia } & d i & \text { Kabupaten }\end{array}$

Sumbawa.

Berdasarkan hasil penelitian yang telah dilakukan bahwa sistem pelajaran full day school Sekolah Dasar Islam Terpadu (SDIT) Samawa Cendekia di Kabupaten Sumbawa menerapkan integrated activities dan integrated curriculum. Artinya semua kegiatan mulai dari belajar, bermain, makan, dan beribadah menjadi sebuah sistem yang utuh dan saling mempengaruhi satu sama lain. Tujuannya, untuk memberikan-menanam nilai-nilai kehidupan harmonis pada anak didik yang setujuan dengan tujuan pendidikan. Disamping itu, Guru dan staf sekolah dituntut untuk lebih banyak kesediaan waktu untuk merancang dan mengembangkan kurikulum dan materi pelajaran lain yang tentunya selaras dengan visi misi lembaga pendidikan tersebut. Tujuannya, untuk menyiapkan peserta didik yang mampu mengerti, memahami, menghayati, dan mengimani ajaran agama sehingga dapat hidup secara harmonis didalam masyarakat. Dampaknya, yang berdampak pada perbaikan, penguatan, dan penyempurnaan peserta didik.

b. Perilaku Sosial Siswa di Sekolah Dasar Islam Terpadu (SDIT) Samawa Cendekia di Kabupaten Sumbawa

Setelah melakukan penelitian bahwa perilaku sosial siswa baik dilingkungan sekolah maupun di masyarakat dapat dikendalikan dengan baik dari hal-hal yang 
dapat merugikan baik dirinya sendiri maupun orang lain. Selain itu, hubungan siswa dengan guru, orang tua, dan masyarakat sangat harmonis. Keadaan tersebut menunjukkan hasil penelitian bahwa perilaku sosial siswa SDIT Samawa Cendekia di Kabupaten Sumbawa sangat baik. Kemudian, interaksi sosial siswa pada sekolah SDIT SC yang menerapkan sistem full day school terlihat baik dan menciptakan hubungan yang harmonis. Dari temuan dilapangan bahwa siswa SDIT SC saling kerja sama, membaur satu sama lain, belajar dan bermain bersama, toleran dalam berkomunikasi dengan teman dan guru,saling menghormati dan saling menghargai baik pada tataran sikap bicara maupun perilaku.

\section{c. Respon orang tua}

Berdasarkan hasil pemantauan penelitian langsung di lapangan bahwa sistem pendidikan full day school tidak membebankan anak didik, orang tua, dan masyarakat. Hal ini disebabkan oleh pelayanan pendidikan full day selalu mengontrol, membina, dan mendidik anak didik. Respon orang dan masyarakat selalu nyaman, tenang, dan aman ketika anaknya dilibatkan dalam pendidikan full day school. Jadi, keberadaan full day school bagi orang tua dan masyarakat sangat baik karena dapat mengoptimalkan pertumbuhanperkembangan anak. Selain itu, membantu para orang tua yang sibuk bekerja sehingga pengawasan ke pada anak berkurang dan anak-anak merasa nyaman selama berada di lingkungan sekolah. Dan membantu anak lebih semangat lagi dalam meningkatkan hafalan khususnya al-qur'an.

\section{Pembahasan}

\section{a. Hakekat Sistem full day school}

Full day school (Susiati dan Asyhar, 2015) adalah salah satu karya cerdik para pemikir dan praktisi pendidikan untuk menyiasati minimnya control orang tua terhadap anak di luar jam-jam sekolah formal sehingga sekolah yang awalnya dilaksanakan 5 sampai 6 jam berubah menjadi 8 bahkan sampai 9 jam. Selaras dengan hal demikian, full day school merupakan model sekolah umum yang memadukan sistem pengajaran Islam secara intensif yaitu dengan memberi tambahan waktu khusus untuk pendalaman keagamaan siswa (Sismanto, nd). Jadi, program full day school pada dasarnya merupakan sebuah upaya menambah waktu dan memperbanyak materi pelajaran serta mempersipkan peserta didik agar menjadi pribadi yang mempunyai kematangan mental, intelektual, skill, pembinaan kejiwaan, mental, dan moral anak.

\section{b. Dampak Sistem Full Day School}

Berdasarkan penelitian yang dilakukan oleh (Jumraeni, nd) 
bahwa sistem full day school memiliki dampak seperti sebagai berikut:

\section{Dampak Positif}

a. Dapat meningkatkan kemampuan kognitif anak. Alasanya, full day school dapat menjadikan siswa berfikir yang mencakup kemampuan intelektual sehingga siswa mampu menggabungkan beberapa ide, gagasan yang dipelajari yang berguana untuk memecahakan masalah.

b. Jumlah pelajaran tentang kepribadian lebih banyak di bandingkan pelajaran umum

Membina siswa menjadi pribadi yang baik dan berperilaku sesuai dengan tuntunan agama. cara ini dilakukan dengan menyatukan beberapa unsur seperti agama, moral, perilaku dan pelajaran umum.

2. Dampak Negatif

a. Siswa kurang berinteraksi dengan orangtua dan lingkungan tempat tinggal. Kondidi ini mempengaruhi perkembangan siswa secara emosional seperti bersosialisasi, bermain dengan keluarga, lingkungan sekitar dengan teman sebaya, dan tetangga penting bagi perkembangan sosial emosional anak.

b. Siswa terlalu lelah yang diakibatkan oleh lamanya disekolah sehingga , kegiatan membaca buku atau keinginan positif lainnya tidak dapat dilakukan lagi.

c. Tingginya tingkat strees dimiliki siswa karena lamanya waktu belajar di sekolah. Hal ini dapat menyebabkan kondisi psikis siswa tertekan karena merasa terpaksa mengikuti pertambahan jam pelajaran. Menelaan kejadian dari dampak sistem full day school yang telah dijelaskan bahwa sekolah yang menerapakan sistem full day school tidak hanya meningkatkan kemampuan siswa secara kognitif tapi juga berdampak buruk bagi perkembangan fisik siswa akibat tekanan belajar yang terlalu lama.

\section{c. Peluang Sistem full Day School}

Sekolah full day school muncul karena terdapat isu yang banyak berkembang dan merusak citra masa depan generasi muda. Hal ini menjadi peluang bagi lembaga pendidikan untuk menerapkan sistem full day school. Seirama dengan hal tersebut, faktor yang menjadikan peluang (Astuti, 2013) sekolah full day banyak bermunculan adalah kurang baiknya lingkungan masyarakat, kurangnya adanya waktu yang disediakan orang tua untuk menemani anaknya belajar, dan kecenderungan anak yang bermain dirumah dan malas untuk belajar.

Pada keadaan yang lain, faktor pendukung pelaksanaan sistem full day school (Baharudin, 2009) adalah kurikulum yang sangat berintegarsi dengan kebutuhan anak, orang tua, dan pemerintah; 
manajemen pendidikan yang sangat teta rapi agar mudah terima-terapkan; sarana dan prasarana yang berdampak positif bagi perkembangan anak didik; dan sumber daya manusia yang sangat kompeten dalam mendidik, melatih, dan membina anak didik.

\section{G. KESIMPULAN DAN SARAN}

\section{Kesimpulan}

Kehadiran implementasi sistem full day Shcool di SDIT samawa cedekia Kabupaten Sumbawa sangat membantu orang tua dan masyarakat. Hal ini muncul karena dari data penelitian yang dihimpun dan dianalisis tidak menunjukkan adanya kerugian-bahaya terhadap anak implementasi pendidikan full day school. Keberadaan SDIT Samawa Cendekia yang menerapkan pendidikan full school sangat memperhatikan tumbuhkembangnya anak didik baik kognitif, afektif, maupun psikomotorik peserta didik. Jadi, Implementasi sistem full day school di SDIT Samawa Cedekia berdampak positif bagi pembagunan pendidikan di Sumbawa Nusa Tenggara Barat.

\section{Saran}

a. Sekolah Dasar Islam Terpadu Samawa Cedekia di Kabupaten Sumbawa harus memperhatikan penuh kebutuhan anak didik.

b. Sekolah Dasar Islam Terpadu Samawa Cedekia di Kabupaten Sumbawa menyesuaikan setiap kegiatan dengan kemampuan dan kondisi kesehatan anak didik

c. Sekolah Dasar Islam Terpadu Samawa Cedekia di Kabupaten Sumbawa Memperhatikan kenyamanan anak didik selama melaksanakan kegiatan pembelajaran dan kenyamanan orang tua/masyarakat dalam menyerahkan kepercayaan sepenuhnya kepada sekolah.

d. Sekolah Dasar Islam Terpadu Samawa Cedekia di Kabupaten Sumbawa Untuk memaksimalkan seluruh potensi siswa mengefektifkan waktu kegiatan belajar baik kurikuler maupun ektrakurikuler.

e. Sekolah Dasar Islam Terpadu Samawa Cedekia di Kabupaten Sumbawa Melakukan kegiatan sosial yang melibatkan anak didik secara langsung agar perilaku sosial anak didik tidak terganggu.

\section{H. REFERENSI}

Marfiah Astuti, 2013. Implementasi Program Fullday School Sebagai UsahaMendorong Perkembangan Sosial Peserta Didik TK Unggulan AlYa'lu Kota Malang, Jurnal Kebijakan dan Pengembangan Pendidikan, 2013)Volume 1, Nomor 2. Malang

Baharuddin, 2010. Pendidikan dan Psikologi Perkembangan. Jogjakarta: Ar-Ruzz Media

Nur Hillah, 2009) Tesis.Pelaksanaan Full Day School di SD Plus Nurul Hikmah Pamekasa (Telaah prlematika perkembangan sosial.

Purnama Susiati dan Ali Asyhar, 2015. Pelaksanaan Full Day Schoolsekolah Dasar Islam Terpadu Al Huda Kecamatan Sangkapura Kabupaten Gresik (Studi Problematika Perkembangan Sosial Peserta Didik. MINU 06 Balikterus 1 dan STAI Hasan Jufri Bawean, CENDEKIA: 
SPECIAL ISSUE

JURNAL TAMBORA VOL. 4 NO. 2A JULI 2020

http://jurnal.uts.ac.id

Social Humaniona

Jurnal Studi Keislaman Volume 1, Nomor 1.

Umar Burkhori, 2010. Ilmu Pendidkan

Islam. Amzah, Jakata. 